\begin{tabular}{|c|l|}
\hline Title & Performances of inert gas glow discharges for reductions of fuel hydrogen retention and helium retention \\
\hline Author(s) & Hino, T.; Kimura, M.; Y amauchi, Y.; Nishimura, K.; A shikawa, N.; Nobuta, Y. \\
\hline Citation & $\begin{array}{l}\text { Fusion Engineering and Design, 85(7-9), 974-978 } \\
\text { https://doi.org/40.1016/.fusengdes.2009.11.005 }\end{array}$ \\
\hline Issue Date & 2010-12 \\
\hline Doc URL & http://hdl.handle.net/2115/49040 \\
\hline Type & article (author version) \\
\hline File Information & FED85-7-9_974-978.pdf \\
\hline
\end{tabular}

Instructions for use 


\title{
Performances of Inert Gas Glow Discharges for Reductions of Fuel Hydrogen Retention and Helium Retention
}

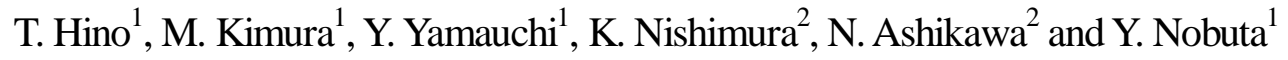 \\ ${ }^{1}$ Laboratory of Plasma Physics and Engineering, Hokkaido University, Sapporo, Japan \\ ${ }^{2}$ National Institute for Fusion Science, Toki, Gifu, Japan
}

\begin{abstract}
In order to clarify the effects of inert gas discharges on the reduction of fuel hydrogen retention, the inert gas discharge has to be similarly conducted in the same apparatus with the same conditions. In the present experiment, first, the hydrogen glow discharge was conducted to measure the fuel hydrogen retention. During the discharge, the amount of retained hydrogen was measured by a technique of residual gas analysis. The inert gas discharges, $\mathrm{He}, \mathrm{Ne}$ and $\mathrm{Ar}$ discharges, then, were carried out after the hydrogen discharge to measure the amount of removed hydrogen. The fractions of removed hydrogen after the $\mathrm{He}, \mathrm{Ne}$ and $\mathrm{Ar}$ discharges were $0.8,0.3$ and 0.1 , respectively. The projected range of helium ion is comparable with that of the hydrogen ion, so that the helium impact desorption well removed the hydrogen. The sputter-etching rate of argon is significantly high, so that the wall surface is quickly covered by the deposited layer. Thus, the removal ratio of the Ar discharge becomes lower than that of the $\mathrm{He}$ or Ne discharge. The $\mathrm{H}_{2}$, Ne or Ar discharge was carried out after the He discharge to reduce the helium retention. It was found that the $\mathrm{Ne}$ and $\mathrm{Ar}$ discharges significantly reduced the helium retention, although the $\mathrm{H}_{2}$ discharge little reduced the helium retention. The reduction of the $\mathrm{Ne}$ discharge was larger than that of the Ar discharge. The amounts of the retained $\mathrm{He}, \mathrm{Ne}$ and $\mathrm{Ar}$ were a few times, two orders and three orders of magnitude smaller than that of hydrogen.
\end{abstract}

Keywords; Fuel hydrogen retention, Helium retention, Wall conditionings, Helium glow discharge, Neon glow discharge, Argon glow discharge

\section{Introduction}

Wall conditionings based upon glow discharge have been widely employed in the large helical device (LHD) [1-2] and tokamak devices [3-4], in order to control the plasma density, to reduce the impurities such as carbon and oxygen at the wall surface and the fuel hydrogen retention in the plasma facing walls. The use of the glow discharge is also effective for the reduction of the in-vessel tritium inventory in the DD or DT discharge.

In the glow discharge, hydrogen, deuterium and helium have been employed as the gas species so far. It is believed that the hydrogen and the helium discharges are effective for reductions of impurities and fuel hydrogen retention, respectively. In the case that the helium glow discharge is conducted, the helium significantly remains in the wall, so that the helium emits to the plasma during the hydrogen main discharge. Thus, it is required to reduce the helium retention before the main discharge with fuel hydrogen. The experimental investigation 
showed that the hydrogen glow discharge little reduced the helium retention [5], but the argon glow discharge significantly reduced the helium retention [6]. In the LHD experiments, neon or argon glow discharge was conducted as the wall conditionings, and it was seen that the neon glow discharge was useful to reduce the fuel hydrogen retention [7].

Though the performances of the inert gas discharges for the reductions of fuel hydrogen retention and helium retention are qualitatively known, the quantitative performances of these inert gas discharges have not been clarified yet. Only the effect of neon glow discharge on the reduction of hydrogen retention was reported in our previous paper [8]. In the present experiments, the ratios of removed hydrogen to the initial hydrogen retention are measured after the hydrogen glow discharge followed by the helium, neon and argon discharges. The ratios of removed helium to the initial helium retention by the hydrogen, neon and argon discharges are also measured after the helium discharge followed by the hydrogen, neon and argon discharges. In addition, the amounts of the retained helium, neon and argon are measured.

\section{Experiments}

The glow discharge apparatus is shown in Figure 1 [5]. This device consists of cylindrical discharge chamber with a stainless steel (SS) liner, gas flow system with mass flow controllers, pumping system consisting of rotary pump and turbo molecular pump, manipulator with a sample holder movable in radial direction and quadruple mass spectrometer, QMS. The glow discharge is produced between $\mathrm{Cu}$ anode at center and SS liner cathode. The ion current to the SS liner was measured to obtain the ion fluence to the wall. The partial pressures of $\mathrm{H}_{2}, \mathrm{He}, \mathrm{Ne}$ and Ar, before, during and after the discharge, were measured by using QMS. The amount of retained or desorbed gas was measured based upon residual gas analysis, RGA. In this measurement, the gas flow rate was kept constant before, during and after the discharge. For example, the reduction of hydrogen partial pressure during the discharge gives the amount of hydrogen retained in the wall. The hydrogen desorption during the inert gas discharge gives the amount of hydrogen desorbed from the wall.

In the present experiment, first, the hydrogen $\left(\mathrm{H}_{2}\right)$ discharge was conducted to measure the amount of retained hydrogen. Then, the helium (He), neon (Ne) and argon (Ar) discharges were carried out to reduce the hydrogen retention. The amount of desorbed hydrogen was measured during the inert gas discharge. Second, the effects of the $\mathrm{H}_{2}$, the $\mathrm{Ne}$ and the Ar glow discharges on the reduction of helium retention were investigated after the He discharge followed by the $\mathrm{H}_{2}$, $\mathrm{Ne}$ and Ar glow discharges. Thirdly, the reduction of the inert gas partial pressure was measured during the inert gas discharge, the $\mathrm{He}, \mathrm{Ne}$ or Ar discharge, so that the amount of retained $\mathrm{He}, \mathrm{Ne}$ or Ar was obtained.

The discharge time was chosen $2 \mathrm{~h}$ for the hydrogen discharge since the hydrogen retention saturated within about $1 \mathrm{~h}$ discharge time. The discharge pressure of hydrogen was $8 \mathrm{~Pa}$, approximately the same the hydrogen gas pressure of glow discharge in LHD. The discharge voltage was $260 \mathrm{~V}$. The average current density was $4 \times 10^{-6} \mathrm{~A} / \mathrm{cm}^{2}$. The discharge time was also taken $2 \mathrm{~h}$ for the $\mathrm{He}, \mathrm{Ne}$ and Ar discharges, since the desorption of hydrogen or helium was 
almost finished within $1 \mathrm{~h}$. The pressure, voltage and average current density of the $\mathrm{He}$ discharge were $8 \mathrm{~Pa}, 240 \mathrm{~V}$ and $(1.2-3) \times 10^{-5} \mathrm{~A} / \mathrm{cm}^{2}$, respectively. The pressure, voltage and current density of the Ne discharge were $8 \mathrm{~Pa}, 450 \mathrm{~V}$ and $(1.1-2.5) \times 10^{-5} \mathrm{~A} / \mathrm{cm}^{2}$, respectively. In the Ar discharge, the pressure, voltage and current density were $(1.3-8) \mathrm{Pa}, 280 \mathrm{~V}$ and $(0.2$ $-2.3) \times 10^{-5} \mathrm{~A} / \mathrm{cm}^{2}$, respectively.

The small SS samples were installed on the sample holder, and exposed to the plasma discharges. Thermal desorption spectroscopy (TDS) was conducted to observe the amounts of retained gases. Atomic force microscopy (AFM) was used to observe the change of the surface morphology by the plasma discharge.

\section{Results}

Figure 2 (a) shows the change of hydrogen partial pressure during the hydrogen glow discharge. The amount of retained hydrogen corresponds to the drop of the hydrogen partial pressure. The average amount of hydrogen retained in the liner wall was $1.5 \times 10^{16} \mathrm{H} / \mathrm{cm}^{2}$. After this discharge, $\mathrm{He}, \mathrm{Ne}$ and Ar glow discharges were conducted for $2 \mathrm{~h}$ to reduce the hydrogen retention. The ion current density during $\mathrm{He}, \mathrm{Ne}$ and Ar glow discharges was changed. Figures 2 (b), (c) and (d) show changes of both inert gas and hydrogen partial pressures during the $\mathrm{He}, \mathrm{Ne}$ and Ar discharges, respectively. In the initial discharge phase, the inert gas pressure decreased and increased to the previous level, and the hydrogen pressure increased and dropped within approximately $1 \mathrm{~h}$. The reduction of the He partial pressure was largest in the inert gas discharges, only a few times smaller than that of hydrogen, as seen in Figure 2 (b). Thus, it is recognized that the helium retained in the wall emits into the plasma during the main discharge shot. The amount of retained argon was smallest, two orders of magnitude smaller than that of helium, since the implantation depth is only several $\AA$. The amount of retained neon was between those of the helium and the argon. The reduction of the hydrogen retention was largest in the case of the He discharge, since the ion implantation depth is comparable with that of hydrogen. However, the reduction of the hydrogen retention in the case of the Ar discharge was smallest because the deposition layer is produced by the sputtered particles, in addition to the short implantation depth. The deposition was examined using a silicon probe. The iron deposition was observed even in the erosion dominant wall. The reduction of the hydrogen retention in the case of the $\mathrm{Ne}$ discharge was again between those in the $\mathrm{He}$ and the $\mathrm{Ar}$ discharges. The removal ratios of hydrogen retention by the $\mathrm{He}, \mathrm{Ne}$ and $\mathrm{Ar}$ discharges are shown in Figure 3 (a). The amounts of retained helium, neon and argon are shown in Figure 3 (b). These results show that the He discharge is quite effective for reduction of hydrogen retention but the He retention becomes comparable with the hydrogen retention. Both the ratio of removed hydrogen and the inert gas retention increased with the ion current density, since the ion fluence becomes high with the discharge time of $2 \mathrm{~h}$.

Figure 4 (a) shows the change of the helium partial pressure during the He discharge. The amount of retained He was as high as $4 \times 10^{15} \mathrm{He} / \mathrm{cm}^{2}$ as shown in Figure 3 (b). After the $\mathrm{He}$ discharge, the $\mathrm{Ne}$ and the Ar discharge were conducted to reduce the He retention. Figures 4 
(b) and (c) show the He desorption during the Ne and the Ar discharges, respectively. The pressure rise of $\mathrm{He}$ in the case of $\mathrm{Ne}$ discharge was sharper than that of Ar discharge, since the helium significantly desorbed. In the case of the He discharge followed by the $\mathrm{H}_{2}$ discharge, almost no hydrogen desorption was observed. However, in the case of the Ne or Ar discharge, the helium desorption was clearly observed. It is conceived that the helium retention was reduced since both the sputtering yield and the mass impact of the neon or argon to the helium are large compared with those of the hydrogen. Figure 5 shows plots of the ratios of removed helium against the current density of inert gas ion. It is seen that the Ne discharge is very effective for reduction of the helium retention, since the deposition layer produced by the sputtering and the implantation depth are thinner compared with those of argon. The present experiment shows that the use of $\mathrm{Ne}$ or Ar discharge is significantly effective for the reduction of helium retention.

The SS samples exposed to the hydrogen discharge and exposed to the hydrogen discharge followed by the inert gas discharge were analyzed by a technique of thermal desorption spectroscopy. Figure 6 (a) shows the desorption spectra of $\mathrm{H}_{2}$ just after the hydrogen discharge and after the hydrogen discharge followed by the Ar discharge. In the spectra, the background was subtracted. The peak around at $440 \mathrm{~K}$ almost disappeared by the Ar discharge. Similar tendency was observed also in the $\mathrm{Ne}$ and the He discharges. The SS samples were also exposed to only the He discharge and the He discharge followed by the inert gas discharge. Figure 6 (b) shows the He spectra just after the He discharge and after the He discharge followed by the Ar discharge. Before the Ar discharge, two peaks at $500 \mathrm{~K}$ and $1100 \mathrm{~K}$ were observed. After the Ar discharge, the peak around at $500 \mathrm{~K}$ almost disappeared. The similar tendency was observed in the case of the He discharge followed by the Ne discharge. It is seen that the helium desorption occurred even at the high temperature, $1100 \mathrm{~K}$. This result suggests that the helium retention is still high even at the high temperature environment.

Figure 7 shows the surface morphologies taken by AFM after the He discharge, (a), and after the He discharge followed by the Ar discharge, (b). After the He discharge, the blister structure was observed. After the Ar discharge, the surface morphology remained the same and no blister was produced by the Ar discharge. However, the peak at $500 \mathrm{~K}$ disappeared after the Ar discharge. Thus, it is regarded that the peak at $1100 \mathrm{~K}$ is due to the rupture of the blisters, and the peak at $500 \mathrm{~K}$ is due to the small size bubbles not seen in the photo by AFM.

\section{Conclusion}

The glow discharges using $\mathrm{H}_{2}, \mathrm{He}$, $\mathrm{Ne}$ and Ar were systematically carried out in the glow discharge apparatus at Hokkaido University. In order to measure the fuel hydrogen retention, $\mathrm{H}_{2}$ glow discharges was conducted. During the discharge, the amount of retained hydrogen was measured by a technique of residual gas analysis. The inert gas discharges were carried out after the hydrogen discharge. The fractions of removed hydrogen after the helium, neon and argon were $0.8,0.3$ and 0.1 , respectively. The projected range of helium ion is comparable with that of the hydrogen ion, so that the helium impact desorption well removed the hydrogen. The 
sputter-etching rate of argon is significantly high, so that the surface layer containing the hydrogen is quickly covered by the deposition of sputtered particles. Thus, the removal ratio of the Ar discharge becomes lower than that of the He discharge. The removal ratio by the $\mathrm{Ne}$ discharge was intermediate between the $\mathrm{He}$ and the Ar discharges. The $\mathrm{Ne}$ and the Ar discharge were carried out after the $\mathrm{He}$ discharge to reduce the helium retention. It was seen that the $\mathrm{Ne}$ and the Ar discharges significantly reduced the helium retention, although the $\mathrm{H}_{2}$ discharge little reduced the He retention. The removal ratio by the Ne discharge was higher than that by the Ar discharge. The amounts of retained $\mathrm{He}, \mathrm{Ne}$ and $\mathrm{Ar}$ were a few times, two orders of magnitude, three orders of magnitude smaller than that of hydrogen. In the fusion device, the He discharge is suitable to reduce both the tritium and deuterium retention. However, the He remains in the wall even if the wall temperature is significantly high. Thus, the He retention has to be reduced in the $\mathrm{D}_{2}$ or DT discharge. If the Ne discharge is conducted, both the fuel hydrogen retention and the helium retention can be well reduced The performances of $\mathrm{He}, \mathrm{Ne}$ and $\mathrm{Ar}$ discharges for the reduction of fuel hydrogen retention, and $\mathrm{Ne}$ and Ar discharges for the reduction of helium retention were systematically investigated in the present study. The present results significantly contribute to the suitable wall conditionings for reductions of particle recycling and in-vessel tritium inventory in large fusion devices and ITER.

\section{Acknowledgements}

This work is supported by the Collaboration Study Program of National Institute for Fusion Science, NIFS08KOBS013, and partly supported by the Grant-in-Aid for Scientific Research (No. 19055003) from the Ministry of Education, Science, Sports and Culture in Japan.

\section{References}

[1] S. Masuzaki, K. Akaishi, H. Funaba, M. Goto, K. Ida, S. Inagaki et al, J. Nucl. Mater., 290-293(2001)12

[2] H. Suzuki , N. Ohyabu, A. Komori, T. Morisaki, S. Masuzaki, J. Miyazawa et al, J. Nucl. Mater., 313-316(2003)297

[3] S. Ishida, K. Abe, K. Yatsu, T. Hino, Y. Takase, H. Ninomiya et al, Nucl. Fusion, 43(2003)606

[4] G.L. Jackson, T.S. Taylor, P.L. Taylor, Nucl. Fusion, 30(1990)2305

[5] T. Hino, Y. Yamauchi, S. Satoh, Y. Hirohata, A. Komori, N. Ashikawa et al, Fusion Eng. Des., 72(2005)339

[6] T. Hino, Y. Higashi, Y. Ymauchi, A. Komori, K. Nishimura, N. Ashikawa, Vacuum, 83 (2009) 493

[7] K. Nishimura, N. Ashikawa, S. Masuzaki, J. Miyazawa, A. Sagara et al. J. Nucl.Mater., 337-339 (2005) 431

[8] Y.Yamauchi, K.Takeda, Y.Nobuta, T.Hino, J. Nucl. Mater., 390 (2009) 1048 


\section{Figure Captions}

Fig.1 Glow discharge apparatus at Hokkaido University.

Fig.2 Change of partial pressures during hydrogen discharge, (a), during He discharge, (b), during Ne discharge, (c), and during Ar discharge, (d).

Fig.3 Ratios of removed hydrogen versus inert ion current density for $\mathrm{He}, \mathrm{Ne}$ and Ar discharge, (a), and amounts of retained $\mathrm{He}, \mathrm{Ne}$ and $\mathrm{Ar}$, (b).

Fig.4 Changes of partial pressures during He discharge, (a), during Ne discharge, (b), and during Ar discharge, (c).

Fig.5 Ratios of removed helium versus of inert ion current density for $\mathrm{Ne}$ and Ar discharges.

Fig.6 Hydrogen desorption spectra before and after Ar discharge, (a), and helium desorption spectra before and after Ar discharge, (b).

Fig.7 Surface morphologies of stainless steel after He discharge, (a), and after the He discharge followed by the Ar discharge, (b). 


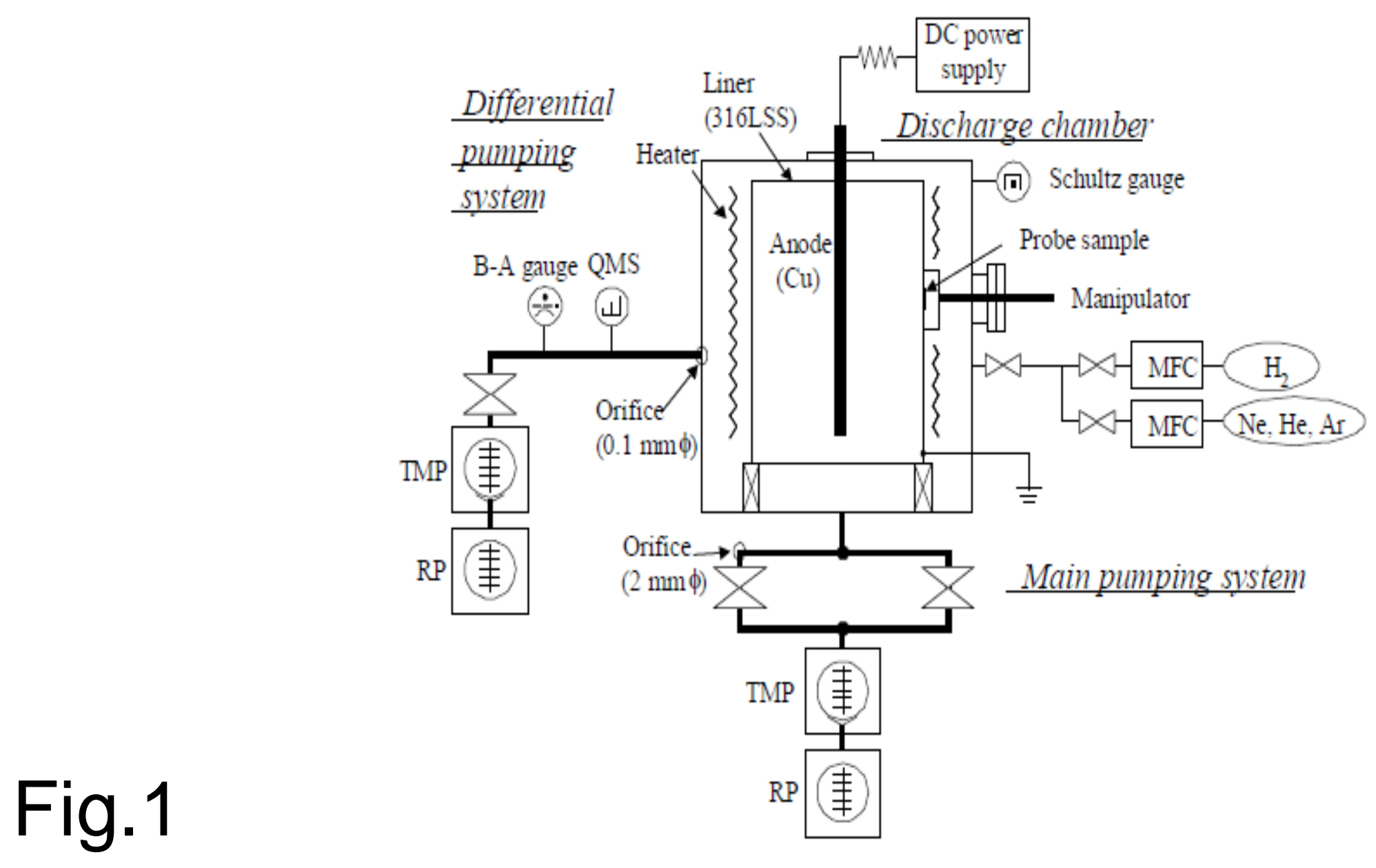


(a) $\mathrm{H}_{2}$

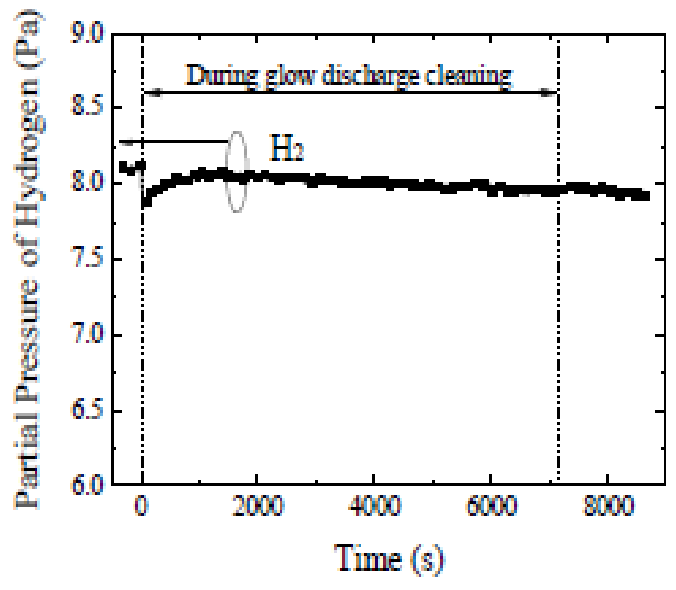

(b) $\mathrm{H}_{2}+\mathrm{He}$

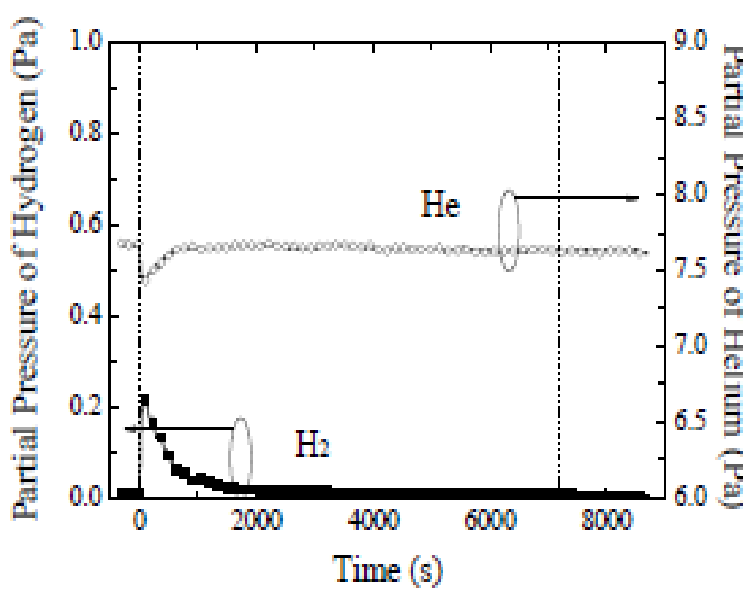

(c) $\mathrm{H}_{2}+\mathrm{Ne}$

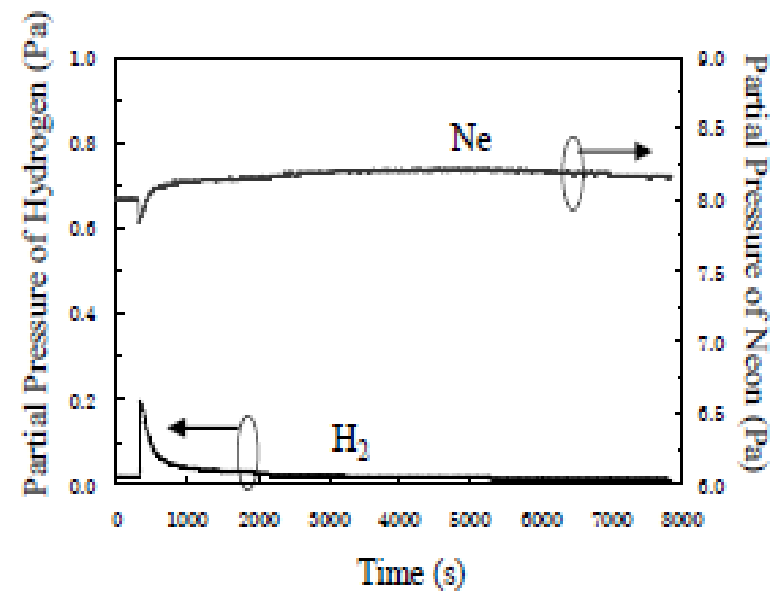

(d) $\mathrm{H}_{2}+\mathrm{Ar}$

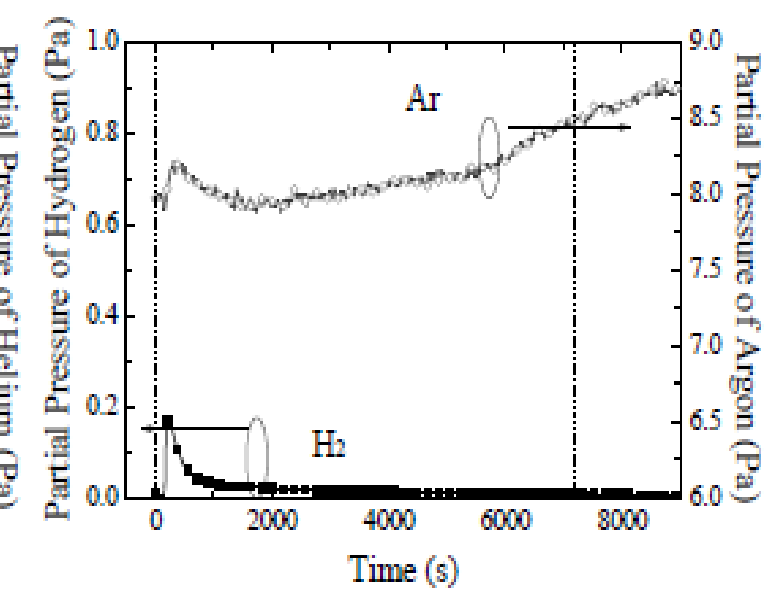


(a)

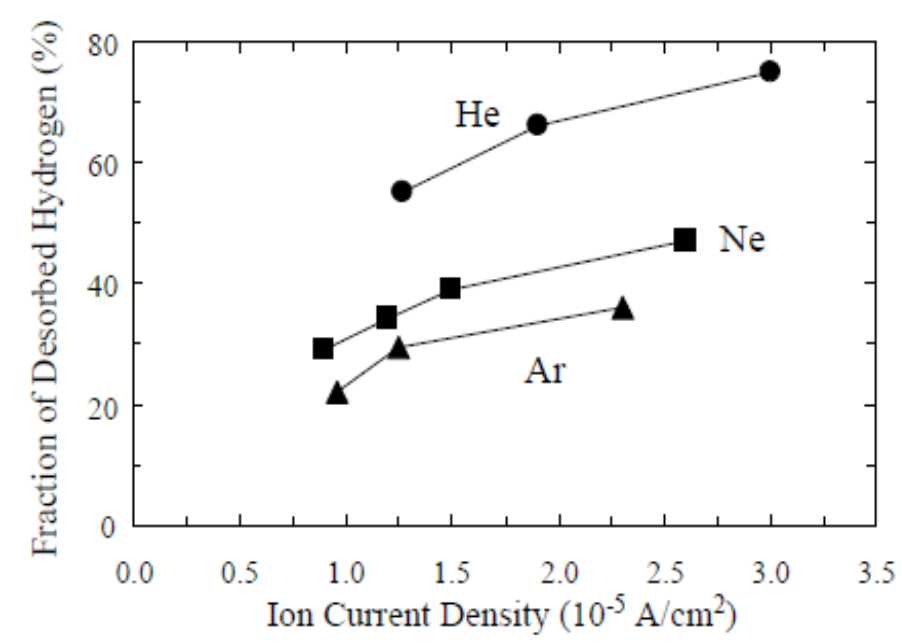

(b)

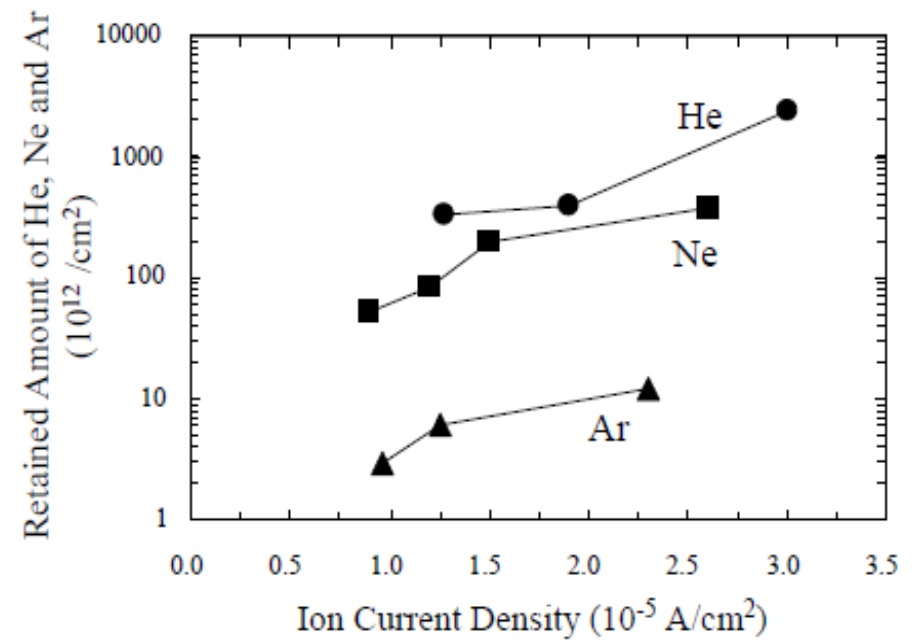

Fig.3 
(a)

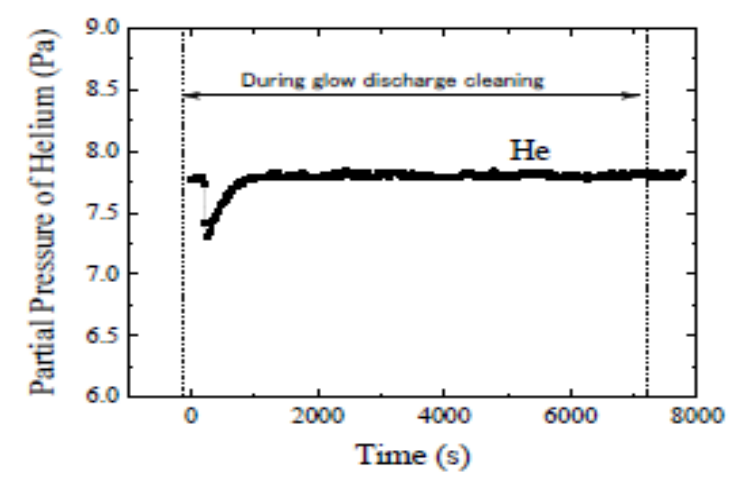

(b)

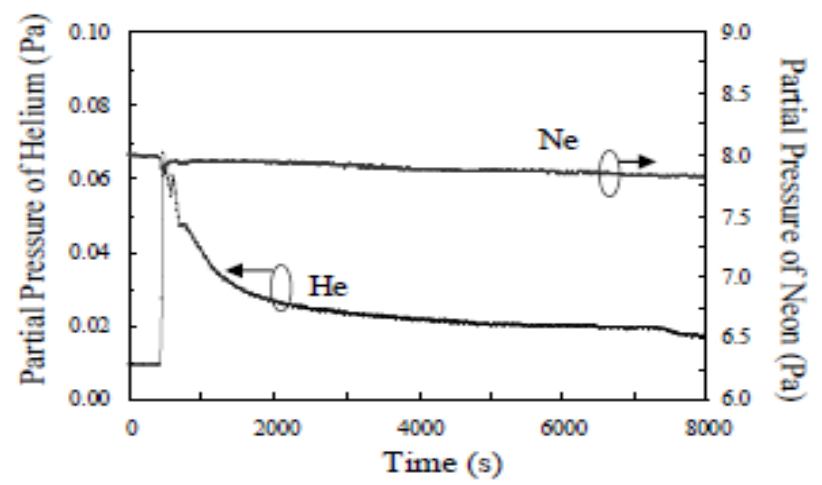

(c)

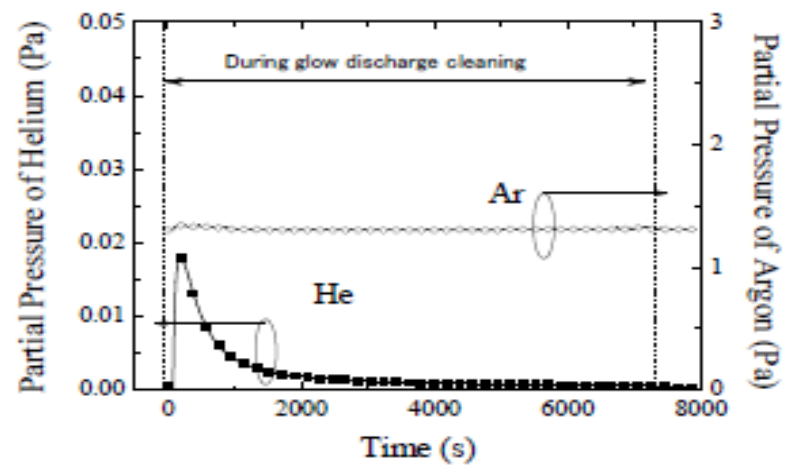




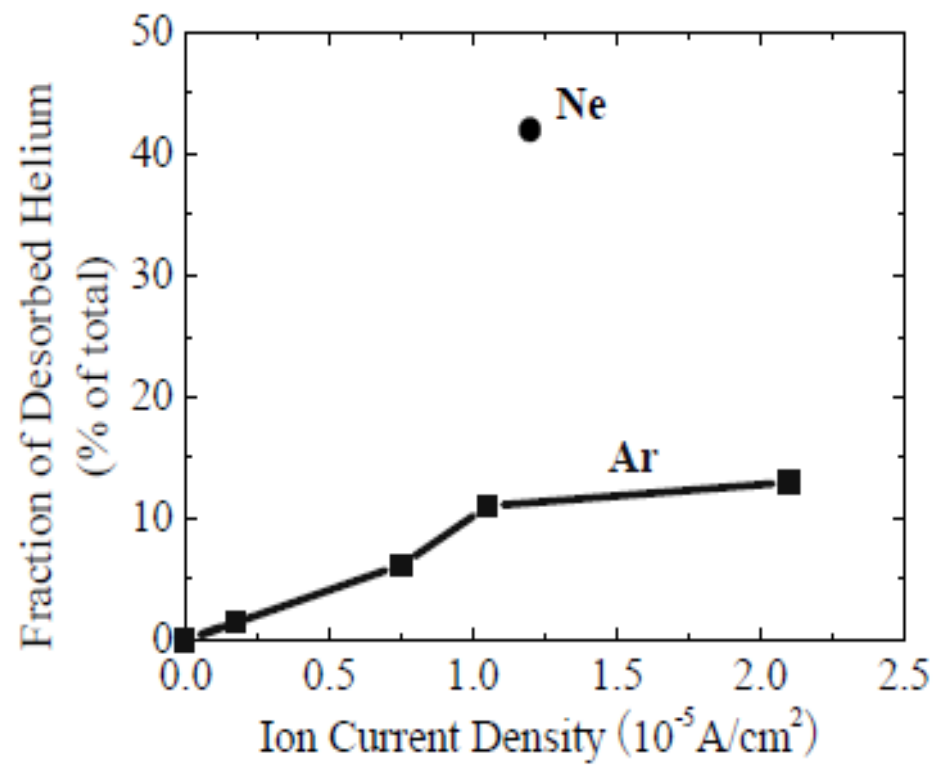

Fig.5 
(a)

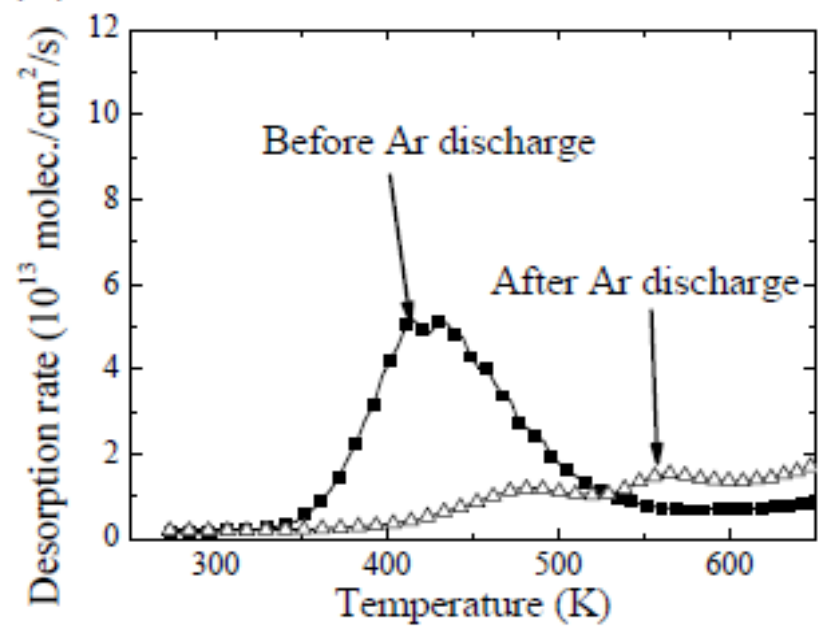

(b)

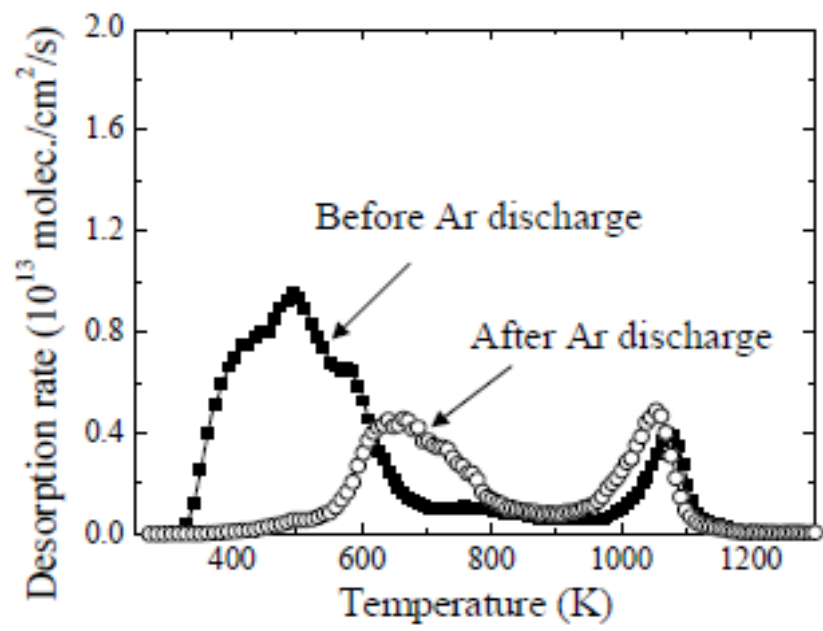




\section{(a)}

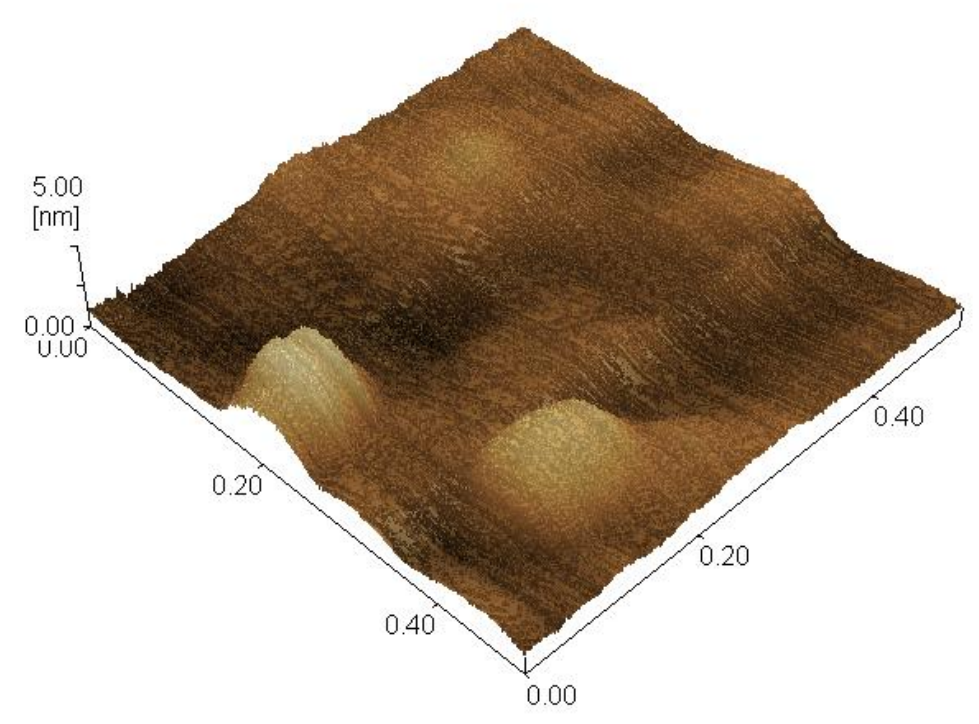

$500.00 \times 500.00[\mathrm{~nm}] \quad Z \quad 0.00-5.00[\mathrm{~nm}]$ (b)

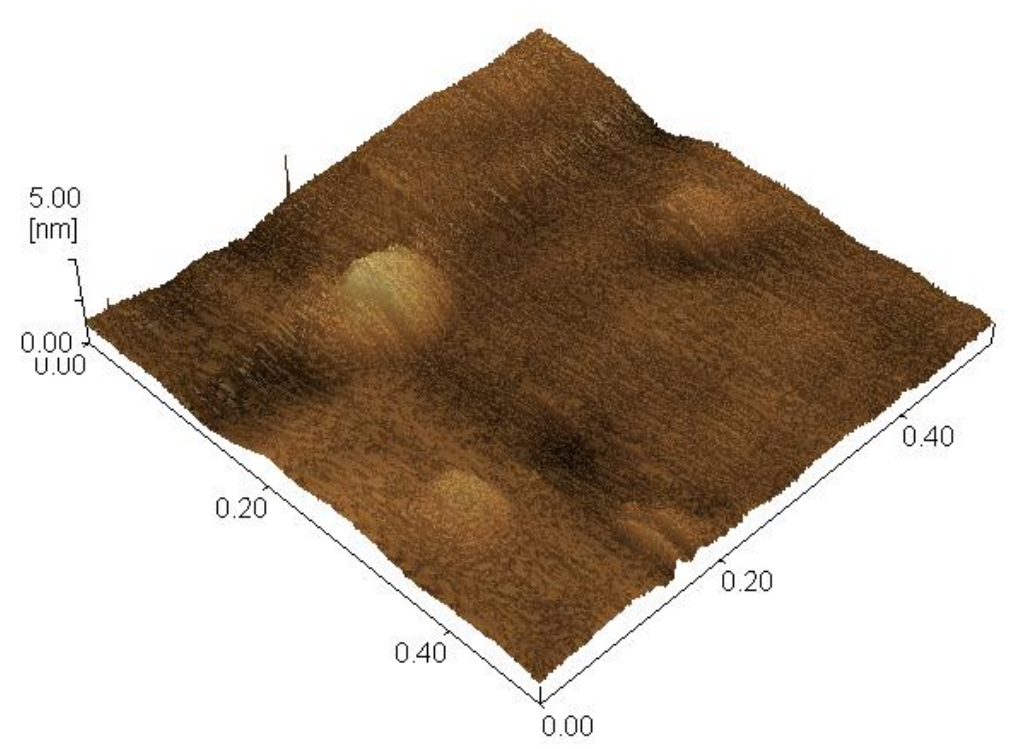

$500.00 \times 500.00[\mathrm{~nm}] \quad Z \quad 0.00-5.00[\mathrm{~nm}]$

Fig.7 